\title{
Tolerância da cebola implantada por semeadura direta ao flumioxazin aplicado em pós-emergência inicial
}

\section{Tolerance of onion implanted by direct sowing to flumioxazin applied in initial post-emergency}

\begin{abstract}
Marcelo Gomes Oliveira ${ }^{1}$, Roque Carvalho Dias ${ }^{2 *}$, Christiane Augusta Diniz Melo ${ }^{3}$, Kassio Ferreira Mendes ${ }^{1}$, Paulo Vinicius Silva ${ }^{4}$, Daniel Valadão Silva ${ }^{5}$, Marcelo Rodrigues Reis ${ }^{6}$

Resumo - O manejo de plantas daninhas na cultura da cebola é prática fundamental para reduzir ou eliminar a interferência de plantas infestantes, uma vez que a cultura, especialmente em sistema de semeadura direta, apresenta crescimento inicial lento e baixa capacidade competitiva. Nesse sentido, para a correta utilização dos herbicidas é necessário conhecer os efeitos proporcionados pelas doses na cultura da cebola bem como quantificar este efeito para os diferentes estádios fenológicos. Diante do exposto, objetivou-se avaliar a tolerância da cebola, em sistema de semeadura direta, ao flumioxazin aplicado em pós-emergência em diferentes estádios fenológicos. $\mathrm{O}$ experimento foi instalado no delineamento inteiramente casualizado, com quatro repetições em arranjo fatorial $4 \times 5+1$, sendo o primeiro fator constituído das doses de flumioxazin $\left(2,5 ; 5,0 ; 7,5\right.$ e $\left.10 \mathrm{~g} \mathrm{ha}^{-1}\right)$ o segundo dos estádios fenológicos em que as aplicações foram realizadas (chicote, $1^{\text {a }}$ folha verdadeira, $2^{\text {a }}$ folha verdadeira, $3^{\mathrm{a}}$ folha verdadeira e $4^{\mathrm{a}}$ folha verdadeira.), além do tratamento adicional (controle sem aplicação). Foram avaliadas a altura das folhas, matéria seca da parte aérea, diâmetro e peso de bulbos. A aplicação do flumioxazin em pós-emergência da cebola reduziu todas as variáveis avaliadas, quando realizada até o estádio de $2^{\mathrm{a}}$ folha verdadeira. Os efeitos negativos foram maiores com o incremento da dose do herbicida nos estádios iniciais de crescimento da cebola. Por outro lado, o flumioxazin aplicado a partir da $3^{\mathrm{a}}$ folha verdadeira, independente da dose, não afetou nenhum dos parâmetros analisados. Após a emissão da terceira folha verdadeira a cebola apresentou tolerância ao flumioxazin.
\end{abstract}

Palavras-chave: Alium cepa L., estádios fenológicos, herbicida, planta daninha

Abstract - Weed management in onion culture is a fundamental practice to reduce or eliminate interference from weeds community, since the crop, especially in direct sowing system, presents slow initial growth and low competitive capacity. In this sense, for the correct use of the herbicides it is necessary to know the effects provided by the doses in the onion crop as well as to quantify this

\footnotetext{
Recebido: Outubro 19, 2017. Aceito: Maio 18, 2018.

${ }^{1}$ Centro de Energia Nuclear na Agricultura - CENA, Universidade de São Paulo - USP, Piracicaba, SP, Brasil.

E-mail: magoliveira102@hotmail.com; kassio_mendes_06hotmail.com

${ }^{2}$ Programa de Pós-graduação em Proteção de Plantas, Faculdade de Ciências Agronômicas - FCA, Universidade Estadual Paulista "Júlio de Mesquita Filho" - UNESP, Avenida Universitária, 3780, Altos do Paraíso, CEP 18610-034, Botucatu, SP, Brasil. E-mail: roquediasagro@gmail.com

${ }^{3}$ Universidade Federal do Triângulo Mineiro - UFTM, Iturama, MG, Brasil. E-mail: chrisadinizmelo@yahoo.com.br

${ }^{4}$ Escola Superior de Agricultura "Luiz de Queiroz" - ESALQ, Universidade de São Paulo - USP, Piracicaba, SP, Brasil.E-mail:paulovsi@yahoo.com.br

${ }^{5}$ Universidade Federal Rural do Semi-Árido - UFERSA, Mossoró, RN, Brasil. E-mail: danielvaladaos@yahoo.com.br

${ }^{6}$ Universidade Federal de Viçosa - UFV, Rio Paranaíba, MG, Brasil. E-mail: marceloreis@ufv.br
} 
effect for the different phenological stages. In view of the above, the purpose of this study was to evaluate the tolerance of the onion in a system of direct sowing to flumioxazin applied in the initial post-emergence in different phonological stages. The experiment was carried out in a completely randomized design, with four replications in factorial arrangement $4 \times 5+1$, the first factor being the flumioxazin $\left(2.5,5.0,7.5\right.$ and $10 \mathrm{~g} \mathrm{ha}^{-1}$ ) doses (whip, 1st leaf, 2nd leaf, 3rd leaf and 4th leaf), as well as additional treatment (control without application). Leaf height, shoot dry matter, diameter and weight of bulb's were evaluated. Application of flumioxazin in post-emergence of onion reduced all the variables assessed when held up until the stage of two true leaves. Negative effects were greater with increase of the dose of the herbicide in the initial stages of growth of the onio. On the other hand, flumioxazin applied from the third dose-independent true leaf did not affect any of the analyzed parameters. After the emission of the third leaf the onion presented tolerance to flumioxazin. Keywords: Alium cepa L., phenological stages, herbicide, weed

\section{Introdução}

A cebola (Allium cepa L.) é considerada a terceira hortaliça mais importante do Brasil, superada apenas pelo tomate e a batata. Em 2017 a área plantada foi de 57 mil hectares em 2017 com produção de $1.605 \mathrm{t}$ e produtividade média de 28,1 t ha ${ }^{-1}$. Com destaque a região Sul com $50 \%$ da produção nacional, seguida pela região Sudeste $(23,9 \%)$, Nordeste $(18,5 \%)$ e Centro-Oeste (7,6\%) (IBGE, 2017).

Diversos fatores podem ocasionar perdas na produção da cultura da cebola, dentre eles destacase a interferência negativa das plantas daninhas, que competem por recursos como água, luz e nutrientes. O cultivo da cebola é caracterizado pela baixa cobertura do solo devido, principalmente, ao lento crescimento e a característica ereta e cilíndrica das folhas, além da baixa produção de biomassa. Esses aspectos permitem a germinação, emergência e crescimento das plantas daninhas durante o ciclo da cultura, caracterizando-a, assim, como uma má competidora (Soares et al., 2003).

A matocompetição durante o ciclo da cultura causa redução da porcentagem de bulbos nas classes de maior tamanho e aumento das classes inferiores, com elevada percentagem de descarte (Hirata et al., 2014). Holm (1956) evidenciou redução de 38, 64 e 98\% da produção da cultura da cebola, instalada via semeadura direta, quando a comunidade infestante conviveu com a cultura por quatro, cinco e seis semanas, respectivamente. Além disso, Soares et al. (2003) observaram reduções de $95 \%$ do peso dos bulbos e de $91 \%$ na produtividade da cultura quando em convivência com as plantas daninhas por até 98 dias, confirmando que sob interferência das plantas daninhas as perdas podem chegar a $100 \%$ na produção comercial (Qasem, 2005; Jean-Simon et al., 2012).

Para o cultivo em larga escala é necessário a adoção de tecnologias que permitam suprimir a concorrência das plantas invasoras e que causem o menor impacto possível a cultura. Entranto, embora existam vários herbicidas indicados para a cultura da cebola, como o flumioxazin (Brasil, 2017), as recomendações de uso se restringem para a implantação por mudas e bulbinhos. As plantas de cebola provenientes de semeadura direta têm se mostrado mais sensíveis aos herbicidas, especialmente no controle de plantas daninhas de folhas largas (eudicotiledôneas), apresentando grande redução na produção, quando estes são utilizados nas doses indicadas para o método de transplantio (Ferreira et al., 1999). Segundo Tripathy et al. (2007), o herbicida flumioxazin atua na inibição da enzima protoporfirinogênio oxidase (PPO), resultando no acúmulo de protoporfirina IX, acarretando a peroxidação de lipídeos, o rompimento celular e a inibição da fotossíntese. A protoporfirina IX é um composto fotodinâmico (Lehnen Junior et al., 1990), que é responsável pela formação de clorofila 
e citocromos através de reações com magnésio e ferro, respectivamente (Vidal e Merotto Júnior, 2001).

O sucesso do manejo das plantas daninhas depende da seletividade do herbicida à cultura. Nesse sentido, a tolerância da cebola ao herbicida é fundamental e está diretamente relacionada à dose aplicada do produto e ao estádio fenológico da cultura. O cultivo de cebola sob semeadura direta sofre grande interferência das plantas daninhas, isto ocorre devido ao lento crescimento e estabelecimento da cultura. O flumioxazin é registrado para aplicações em pós-emergência da cultura da cebola a partir do estádio de quarta folha verdadeira (Brasil, 2017), dessa maneira, espera-se que o uso do flumioxazin em estádios fenológicos iniciais aumente o controle das plantas daninhas e reduza sua interferência no desenvolvimento inicial da cultura da cebola.

Diante do exposto, objetivou-se com esse trabalho teve por objetivo avaliar a tolerância da cebola, proveniente de semeadura direta, ao herbicida flumioxazin aplicado em pós-emergência, em diferentes doses e estádios fenológicos da cultura.

\section{Material e métodos}

O experimento foi realizado em casa de vegetação, em delineamento inteiramente casualizado, com quatro repetições. Os tratamentos foram arrajandos em esquema fatorial $4 \times 5+1$, sendo o primeiro fator constituído das doses do herbicida flumioxazin (Flumyzin 500, WP, 500 g i.a. $\mathrm{kg}^{-1}$, Sumitomo Chemical Co. Ltda): 2,$5 ; 5,0 ; 7,5 \mathrm{e} 10 \mathrm{~g} \mathrm{ha}^{-1} \mathrm{e}$ o segundo dos estádios fenológicos da cultura em que as aplicações foram realizadas (chicote, $1^{\text {a }}$ folha verdadeira, $2^{\mathrm{a}}$ folha verdadeira, $3^{\mathrm{a}}$ folha verdadeira, $4^{\mathrm{a}}$ folha verdadeira), além de um controle sem aplicação.

Foi utilizado como substrato um Latossolo Vermelho Distroférrico (EMBRAPA, 2013) cuja as propriedades físico-químicas encontram-se na Tabela 1, coletado em Rio Paranaíba -MG em uma área de cerrado desmatado e em pousio, na profundidade de $0-10 \mathrm{~cm}$. A adubação mineral foi realizada utilizando-se $135 \mathrm{~kg} \mathrm{ha}^{-1} \mathrm{de} \mathrm{N}, 45 \mathrm{~kg} \mathrm{ha}^{-1}$ de $\mathrm{P}_{2} \mathrm{O}_{5}$ e $135 \mathrm{~kg} \mathrm{ha}^{-1}$ de $\mathrm{K}_{2} \mathrm{O}$, respectivamente, nas formas de sulfato de amônia, fosfato monoamônio (MAP) e cloreto de potássio, respectivamente, segundo as recomendações de Ribeiro et al. (1999). Durante a condução dos experimentos os vasos foram irrigados sempre que necessário, visando manter a umidade necessária para o desenvolvimento das plantas.

Foram semeadas dez sementes de cebola, híbrido "Sirius", em vasos com capacidade para 5,5 $\mathrm{dm}^{3}$ de solo, o desbaste foi realizado três dias após a emergência (DAE), mantendo-se cinco plantas por unidade experimental. Os tratamentos ocorreram aos 10 DAE (chicote), 25 DAE ( $1^{\text {a }}$ folha verdadeira), $40 \operatorname{DAE}\left(2^{\mathrm{a}}\right.$ folha verdadeira), $53 \mathrm{DAE}$ ( $3^{\mathrm{a}}$ folha verdadeira) e $71 \mathrm{DAE}$ ( $4^{\mathrm{a}}$ folha verdadeira).

Para isso, utilizou-se um pulverizador costal pressurizado com $\mathrm{CO}_{2}$ à $200 \mathrm{kPa}$ de pressão, munido de barra com duas pontas de jato plano (tipo "leque") 110-02, espaçadas de 0,5 m, a uma altura de aproximadamente $50 \mathrm{~cm}$ em relação as plantas de cebola e volume de calda equivalente a $200 \mathrm{~L} \mathrm{ha}^{-1}$.

Tabela 1. Características físico-químicos do Latossolo Vermelho Distroférrico de textura argilosa utilizado no experimento.

\begin{tabular}{|c|c|c|c|c|c|c|}
\hline \multicolumn{2}{|c|}{ pH } & $\mathbf{A l}^{3+}$ & $\mathbf{H}^{+}+\mathbf{A} \mathbf{l}^{3+}$ & $\mathrm{Ca}^{2+}+\mathrm{Mg}^{2+}$ & $\mathrm{Ca}^{2+}$ & \multirow{2}{*}{$\frac{\mathrm{K}^{+}}{\left(\mathrm{mg} \mathrm{dm}^{-3}\right)}$} \\
\hline & & \multicolumn{4}{|c|}{$\left(\mathrm{cmol}_{\mathrm{c}} \mathrm{dm}^{-3}\right)$} & \\
\hline \multicolumn{2}{|c|}{6,00} & $\mathbf{0 , 0 0}$ & $\mathbf{3 , 5 0}$ & 4,60 & 3,60 & 100 \\
\hline M.O. & $\mathbf{P}$ & CTC $(\mathrm{pH}=7)$ & $\mathbf{V}$ & Areia & Silte & Argila \\
\hline$\left(\operatorname{dag} \mathrm{dm}^{-3}\right)$ & $\left(\mathrm{mg} \mathrm{dm}^{-3}\right)$ & $\left(\mathrm{cmol}_{\mathrm{c}} \mathrm{dm}^{-3}\right)$ & $(\%)$ & & $($ dag kg-1) & \\
\hline 2,40 & 13,90 & 8,37 & 58,00 & 32,90 & 11,70 & 55,40 \\
\hline
\end{tabular}

M.O. = matéria orgânica; $\mathrm{CTC}=$ capacidade de troca catiônica; $\mathrm{V}=$ saturação por bases. 
Aos 115 DAE, foram realizadas as avaliações e, em seguida, a colheita dos bulbos. Foram avaliadas a altura das plantas com auxílio de uma régua graduada, medindo-se a altura entre o solo e o ápice da folha mais alta. As folhas foram cortadas rente ao solo, acondicionadas em sacos de papel e secas em estufa de circulação forçada de ar, a temperatura média de $70{ }^{\circ} \mathrm{C}$, até atingir massa constante e, posteriormente, pesadas em balança analítica. Os bulbos foram lavados em água corrente e secos, sendo posteriormente medido o diâmetro equatorial por um paquímetro digital e pesado em balança analítica.

Os dados obtidos foram submetidos à análise de variância pelo teste $F(p<0,05)$. Quando constatada diferenças significativas foi empregado o teste de Dunnet ( $\mathrm{p}<0,05)$, para comparação das médias dos tratamentos com a testemunha e análise de regressão para verificação do comportamento das características as doses empregadas e a confecção dos gráficos com o auxílio do programa Sigmaplot versão 12.0

\section{Resultados e discussão}

A matéria seca da parte aérea (MSPA) foi reduzida em todas as doses do flumioxazin no estádio de chicote e nas doses de 7,5 e 10,0 $\mathrm{g} \mathrm{ha}^{-1}$ i.a. nos três primeiros estádios vegetativos (chicote, $1^{\mathrm{a}} \mathrm{e} 2^{\mathrm{a}}$ folha verdadeira), quando comparado ao controle (sem herbicida) (Tabela 2). Verificou-se redução de 27, 78, 87 e $100 \%$ nas doses de 2,5, 5, 7,5 e 10,0 $\mathrm{g} \mathrm{ha}^{-1}$ i.a., respectivamente, aplicadas no estádio de chicote em relação ao controle, indicando elevada sensibilidade da cultura ao herbicida neste estádio. A partir da terceira folha verdadeira, não houve diferenças para a MSPA, independente das doses utilizadas. $\mathrm{O}$ aumento das doses do flumioxazin reduziu linearmente a MSPA da cebola quando aplicadas nos estádios de chicote, $1^{\mathrm{a}}$ e $2^{\mathrm{a}}$ folha verdadeira (Figura 1A).

A aplicação do flumioxazin em todas as doses avaliadas, afetou negativamente a altura de plantas da cebola, quando aplicado no estádio de chicote da cultura (Tabela 3). Nesse mesmo estádio, constatou-se redução linear do crescimento em altura das folhas com o aumento da dose do herbicida (Figura 1B). Nos demais estádios de desenvolvimento não foi notada nenhuma alteração da variável, independente da dose utilizada.

As plantas de cebola apresentaram redução do diâmetro do bulbo (DB) em relação ao controle, desde o estádio de chicote até a segunda folha verdadeira em todas as doses avaliadas (Tabela 4). No que se refere ao peso de bulbo verificou-se, em todas as doses, nos estádios de chicote e $1^{\text {a }}$ folha verdadeira os menores valores dessa variável,

Tabela 2. Matéria seca da parte aérea da cebola após a aplicação do flumioxazin em diferentes doses e estádios fenológicos.

\begin{tabular}{|c|c|c|c|c|}
\hline \multicolumn{5}{|c|}{ Matéria seca da parte aérea (g) } \\
\hline \multirow{2}{*}{ Estádio fenológico da cultura } & \multicolumn{4}{|c|}{ Dose $\left(\mathrm{g} \mathrm{ha}^{-1}\right.$ i.a. $)$} \\
\hline & 2,5 & $\mathbf{5 , 0}$ & 7,5 & 10,0 \\
\hline Chicote & $3,04^{*}$ & $0,90^{*}$ & $0,54 *$ & $0,00 *$ \\
\hline $1^{\text {a }}$ Folha Verdadeira & 4,15 & 3,04 & $2,37 *$ & $2,00^{*}$ \\
\hline $2^{\mathrm{a}}$ Folha Verdadeira & 3,96 & 2,93 & $2,39 *$ & $2,16^{*}$ \\
\hline $3^{\text {a }}$ Folha Verdadeira & 3,70 & 3,42 & 3,88 & 4,18 \\
\hline $4^{\text {a }}$ Folha Verdadeira & 4,07 & 3,79 & 4,18 & 3,83 \\
\hline Controle & \multicolumn{4}{|c|}{4,17} \\
\hline DMS (Dunnett - 5\%) & 0,73 & 1,73 & 1,57 & 0,73 \\
\hline C.V. $(\%)$ & 9,80 & 29,11 & 27,56 & 13,77 \\
\hline
\end{tabular}

Médias seguidas por asterisco $(*)$ diferem estatisticamente do controle pelo teste de Dunnett a $5 \%$ de probabilidade. DMS = diferença mínima significativa; C.V. $(\%)=$ Coeficiente de variação. 

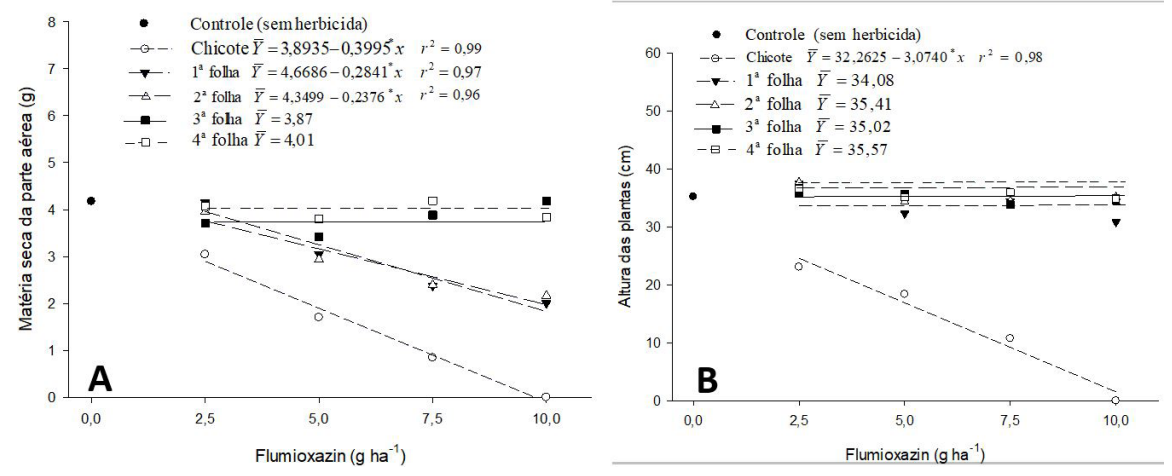

Figura 1. Matéria seca da parte aérea $(\mathrm{g})(\mathrm{A})$ e altura de plantas $(\mathrm{cm})(\mathrm{B})$ da cebola submetida à aplicação de doses do herbicida flumioxazin em diferentes estádios fenológicos.

Tabela 3. Altura das plantas de cebola após a aplicação do flumioxazin em diferentes doses e estádios fenológicos.

\begin{tabular}{ccccc}
\hline \multirow{2}{*}{ Estádio fenológico da cultura } & \multicolumn{4}{c}{ Altura das plantas (cm) } \\
\cline { 2 - 5 } & $\mathbf{4}$ & $\mathbf{5 , 0}$ & $\mathbf{7 , 5}$ & $\mathbf{1 0 , 0}$ \\
\cline { 2 - 5 } & $\mathbf{2 , 5}$ & $24,37^{*}$ & $22,75^{*}$ & $0,00^{*}$ \\
\hline Chicote & $23,07^{*}$ & 32,32 & 34,48 & 30,83 \\
1 $^{\text {a }}$ Folha Verdadeira & 37,55 & 34,40 & 34,49 & 35,18 \\
2 $^{\mathrm{a}}$ Folha Verdadeira & 37,73 & 35,68 & 33,88 & 34,60 \\
3 $^{\mathrm{a}}$ Folha Verdadeira & 35,73 & 35,10 & 35,98 & 34,95 \\
4 $^{\mathrm{a}}$ Folha Verdadeira & 36,60 & & 35,24 & \\
Controle & & 5,47 & 6,36 & 5,04 \\
DMS (Dunnett - 5\%) & 2,78 & 8,54 & 9,94 & 9,07 \\
C.V. (\%) & 4,15 & &
\end{tabular}

Médias seguidas por asterisco $\left(^{*}\right)$ diferem estatisticamente do controle pelo teste de Dunnett a $5 \%$ de probabilidade. DMS = diferença mínima significativa; C.V. $(\%)=$ Coeficiente de variação.

Tabela 4. Diâmetro de bulbo da cebola após a aplicação do flumioxazin em diferentes doses e estádios fenológicos.

\begin{tabular}{|c|c|c|c|c|}
\hline \multirow{3}{*}{ Estádio fenológico da cultura } & \multicolumn{4}{|c|}{ Diâmetro de bulbo (g) } \\
\hline & \multicolumn{4}{|c|}{ Dose (g ha ${ }^{-1}$ i.a.) } \\
\hline & 2,5 & 5,0 & 7,5 & 10,0 \\
\hline Chicote & $24,54^{*}$ & $21,97 *$ & $14,08^{*}$ & $0,00^{*}$ \\
\hline $1^{\text {a }}$ Folha Verdadeira & $25,67 *$ & $24,37 *$ & $26,13^{*}$ & $19,97 *$ \\
\hline $2^{\mathrm{a}}$ Folha Verdadeira & $29,50^{*}$ & $28,15^{*}$ & $23,04 * b$ & $24,24 *$ \\
\hline $3^{\text {a }}$ Folha Verdadeira & 35,71 & 32,83 & 31,89 & 34,87 \\
\hline $4^{\text {a }}$ Folha Verdadeira & 38,59 & 35,67 & 37,06 & 37,27 \\
\hline Controle & \multicolumn{4}{|c|}{38,44} \\
\hline DMS (Dunnett - 5\%) & 7,52 & 9,04 & 7,63 & 6,66 \\
\hline C.V. $(\%)$ & 12,02 & 15,33 & 13,74 & 13,23 \\
\hline
\end{tabular}

Médias seguidas por asterisco $(*)$ diferem estatisticamente do controle pelo teste de Dunnett a $5 \%$ de probabilidade. DMS = diferença mínima significativa; C.V. (\%) = Coeficiente de variação. 
Tabela 5. Peso do bulbo da cebola após a aplicação do flumioxazin em diferentes doses e estádios fenológicos.

\begin{tabular}{|c|c|c|c|c|}
\hline \multirow{3}{*}{ Estádio fenológico da cultura } & \multicolumn{4}{|c|}{ Peso de bulbo (g) } \\
\hline & \multicolumn{4}{|c|}{ Dose (g ha ${ }^{-1}$ i.a.) } \\
\hline & 2,5 & 5,0 & 7,5 & 10,0 \\
\hline Chicote & $12,37^{*}$ & $10,66^{*}$ & $5,19 *$ & $0,00 *$ \\
\hline $1^{\text {a }}$ Folha Verdadeira & $12,08^{*}$ & $11,68^{*}$ & $10,24 *$ & $7,97^{*}$ \\
\hline $2^{\text {a }}$ Folha Verdadeira & 21,47 & 18,71 & $13,27 *$ & $10,46^{*}$ \\
\hline $3^{\text {a }}$ Folha Verdadeira & 24,47 & 23,97 & 24,08 & 24,71 \\
\hline $4^{\text {a }}$ Folha Verdadeira & 25,78 & 25,13 & 23,88 & 26,13 \\
\hline Controle & \multicolumn{4}{|c|}{26,38} \\
\hline DMS (Dunnett - 5\%) & 5,75 & 9,13 & 6,35 & 5,69 \\
\hline C.V. $(\%)$ & 14,44 & 24,10 & 18,95 & 18,30 \\
\hline
\end{tabular}

Médias seguidas por asterisco $(*)$ diferem estatisticamente do controle pelo teste de Dunnett a $5 \%$ de probabilidade. DMS = diferença mínima significativa; C.V. $(\%)=$ Coeficiente de variação.

diferindo-se do controle (Tabela 5). Observou-se, ainda, redução do peso dos bulbos em 100\% na maior dose na fase de chicote. Nas doses superiores (7,5 e $10 \mathrm{~g} \mathrm{ha}^{-1}$ i.a.) redução do peso do bulbo foi observada também em plantas de cebola submetidas à aplicação no estádio da $2^{\mathrm{a}}$ folha verdadeira. Ao analisar o efeito do herbicida para cada estádio da planta, notou-se redução linear tanto no diâmetro quanto no peso dos bulbos com o aumento das doses do herbicida, quando aplicadas no estádio de chicote, $1^{\mathrm{a}}$ e $2^{\mathrm{a}}$ folha verdadeira (Figura $2 \mathrm{~A}$ e $2 \mathrm{~B}$ ).

$\mathrm{O}$ estádio de chicote é o início da fase de crescimento da parte aérea da cebola em que há menor quantidade de cera nas folhas, podendo ser um dos motivos da menor tolerância observada. Ferreira e Costa (1982) e Oliveira Júnior et al. (1997) relataram que a cerosidade foliar é um dos mecanismos de tolerância da cebola a ação de herbicidas aplicados em pós-emergência. Ao contrário, a maior quantidade de cera nas folhas é possivelmente a causa da maior tolerância em estádios mais avançados de desenvolvimento. Além disso, em estádios mais avançados da cebola verifica-se a formação de bainhas imbricadas, o que confere uma maior proteção em relação ao contato do herbicida (Carvalho et al., 2014).

A redução da altura e matéria seca da parte aérea ocasionada pela aplicação do flumioxazin é devido ao mecanismo de ação do herbicida, que consiste na inibição da enzima protoporfirinogênio oxidase (PROTOX ou PPO). Essa inibição acarreta o acúmulo de protoporfirinogênio IX, que é uma molécula extremamente reativa, que, na presença de luz e oxigênio, produz o oxigênio singleto e radicais livres que causam a oxidação dos lipídios de membrana, o que resulta em dano irreversível em plantas suscetíveis (Tripathy et al., 2007). Assim, as maiores doses podem afetar diretamente o crescimento e desenvolvimento posterior da cebola, visto que a cultura é composta por um número reduzido de folhas e, dessa forma, a interferência na área fotossintética ativa da planta pode comprometer a produção.

Ferreira (1985) encontraram redução da matéria seca da cebola "Granex 33" em semeadura direta, culminando em menores produções totais e comerciais mensuradas pelo diâmetro dos bulbos com o uso de aplicação fracionada de oxyfluorfen aos 18 e 51 dias após a semeadura. Tais resultados evidenciam a maior intoxicação da cultura causada por herbicidas nos estádios iniciais. Rozanski et al. (2002) em estudos em campo, constataram que o flumioxazin aplicado em pós-emergência nas doses de 25 até $75 \mathrm{~g} \mathrm{ha}^{-1}$ i.a. apresentou sintomas de fitointoxicação, com recuperação posterior da cultura. Já Souza et al. 

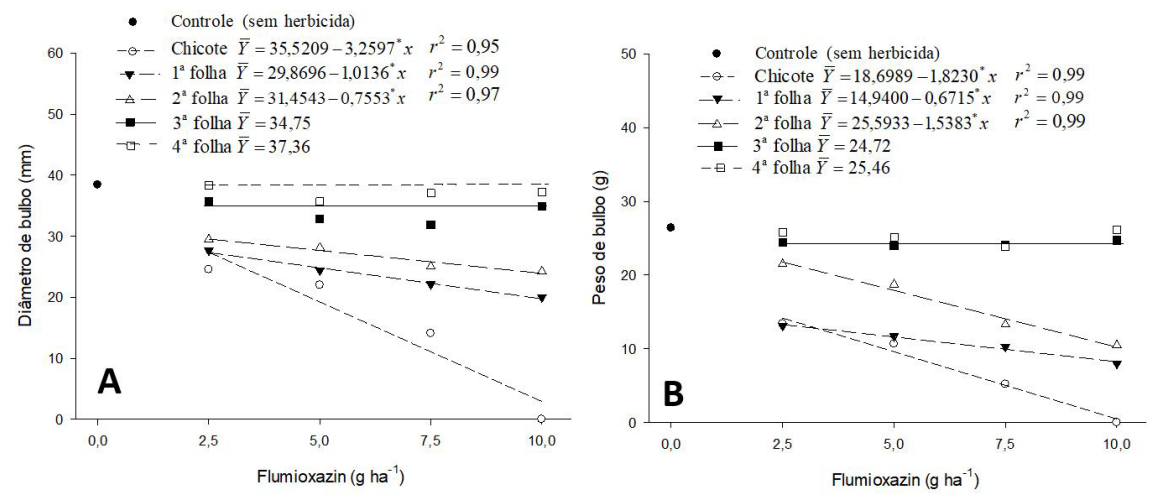

Figura 2. Diâmetro de bulbo $(\mathrm{mm})(\mathrm{A})$ e peso de bulbo $(\mathrm{g})(\mathrm{B})$ da cebola submetida à aplicação de doses do herbicida flumioxazin em diferentes estádios fenológicos.

(2015), em aplicações sequências utilizando o flumioxazin $70 \mathrm{~g} \mathrm{ha}^{-1}$ i.a. aos 30 dias após o transplante das mudas, observaram reduções na altura das plantas e na produtividade de bulbos comerciais. Estes resultados coincidem com o trabalho de Oliveira Júnior et al. (1997) constatando que a tolerância ao herbicida oxyfluorfen de três cultivares de cebola aumentaram com a idade após a emergência. Os resultados do presente trabalho corroboram com os encontrados por Durigan et al. (2005) que também demonstraram a sensibilidade da cultura em estádios mais jovens com aumento das doses de flumioxazin de 80 até $240 \mathrm{~g} \mathrm{ha}^{-1}$ i.a.

\section{Conclusão}

A cebola em semeadura direta apresenta tolerância ao flumioxazin até $10 \mathrm{~g} \mathrm{ha}^{-1}$ aplicado em pós-emergência a partir da terceira folha verdadeira da cultura.

\section{Referências}

Brasil. MAPA - Ministério da Agricultura. AGROFIT - Sistema de Agrotóxicos Fitossanitários. Brasília, 2017. Disponível em: <http://www.agricultura. gov.br/servicos-e-sistemas/sistemas/agrofit $>$. Acesso em: 03 jul. 2017.

Carvalho, D.R.; de Lima, M.F.P.; Freitas, F.C.L.; Silva, M.G.O.; Rocha, P.R.R.; Grangeiro, L.C.
Eficiência do oxyfluorfen no controle de plantas daninhas na cultura da cebola transplantada irrigada por gotejamento. Revista Agro@mbiente Online, v.8, n.1, p.127-133, 2014.

Durigan, J.C.; Silva, M.R.M.; Azania, A.A.P.M. Eficácia e seletividade do herbicida flumioxazin aplicado em pré-emergência na cultura transplantada da cebola. Revista Brasileira de Herbicidas, v.4, n.3, p.11-17, 2005.

EMBRAPA - Empresa Brasileira de Pesquisa Agropecuária. Centro Nacional de Pesquisa Agropecuária de Solos. Sistema brasileiro de classificação de solos. Brasília: Embrapa Produção de Informação; Brasília: Embrapa Solos, 2013. $154 \mathrm{p}$.

Ferreira, J.C. Avaliação de herbicidas aplicados em pré e pós-emergência na cultura da cebola (Allium cepa L.). Planta Daninha, v.9, n.1-2, p.97-105, 1985.

Ferreira, L.R.; Durigan, J.C.; Churata-Masca, M.G.C. Seletividade de herbicidas para cebola em semeadura direta. Planta Daninha, v.17, n.1, p.53-62, 1999.

Ferreira, P.V.; Costa, C.P. Efeito da cerosidade foliar na reação de variedades de cebola (Allium cepa L.) a herbicidas de pós-emergência. Planta Daninha, v.5, n.2, p.29-35, 1982. 
Hirata, A.C.S.; Narita, N.; Rós, A.B. Cobertura morta no manejo de plantas daninhas em cebola. Pesquisa \& Tecnologia, v.11, n.1, p.1-4, 2014. Holm, L.G. Some quantitative aspects of weed competition in vegetable crops. Weeds, v.4, n.2, p.111-123, 1956.

IBGE - Instituto Brasileiro de Geografia e Estatística. Produção agrícola municipal. Rio de Janeiro, 2017. Disponível em: <http://www. sidra.ibge.gov.br>. Acesso em: 02 jul. 2017.

Jean-Simon, L.; Mont-Gerard, J.; Sander, J.J. Effect of early season weed competition duration on onion yield. Proceedings of the Annual Meeting of the Florida State Horticultural Society, v.125, p.226-228, 2012.

Lehnen Junior, L.P.; Sherman, T.D.; Becerril, J.; Duke, S.O. Tissue and cellular localization of acifluorfen-induced porphyrins in cucumber cotyledons. Pesticide Biochemistry and Physiology, v.37, n.3, p.239-248, 1990.

Oliveira Junior, R.S.; Silva, J.F.; Ferreira, L.R.; Reis, F.P. Sensibilidade de cultivares de cebola (Allium cepa L.) implantados por semeadura direta ao oxyfluorfen aplicado em diferentes estádios de desenvolvimento da planta. Ceres, v.44, n.251, p.1-16, 1997.

Qasem, J.R. Critical period of weed competition in onion (Allium cepa L.) in Jordan. Jordan Journal of Agricultural Sciences, v.1, n. 1, p.32-42, 2005.
Ribeiro, A.C.; Guimarães, P.T.G.; Alvarez, V.H. Recomendação para o uso de corretivos e fertilizantes em Minas Gerais: $5^{\text {a }}$ aproximação. Viçosa: Comissão de Fertilidade do Solo do Estado de Minas Gerais, 1999. 359p.

Rozanski, A.; Burga, C.A.; Costa, E.A.D.; Matallo, M.B. Efeito do herbicida flumioxazin nas plantas daninhas e na cultura da cebola. Londrina: SBCPD, 2002. (Boletim Informativo Ciência das Plantas Daninhas, v.8, n.1).

Soares, D.J.; Pitelli, R.A.; Braz, L.T.; Gravena, R.; Toledo, R.E.B. Períodos de interferência das plantas daninhas na cultura de cebola (Allium сера) transplantada. Planta Daninha, v.21, n.3, p.387-396, 2003.

Souza, J.I.; Goes Maciel, C.D.; Jadoski, S.O.; Pazinato da Silva, A.A.; Matias, J.P. Resposta à aplicação sequencial tardia de herbicidas na cultura da cebola transplantada em diferentes arranjos de plantas. Revista Brasileira de Tecnologia Aplicada nas Ciências Agrárias, v.8, n.2, p.25-33, 2015.

Tripathy, B.C.; Mohapatra, A.; Gupta, I. Impairment of the photosynthetic apparatus by oxidative stress induced by photosensitization reaction of protoporphyrin IX. Biochimica et Biophysica Acta, v.1767, n.6, p.860-868, 2007. PMid:17459329.

Vidal, R.A.; Merotto Júnior, A. Herbicidologia. Porto Alegre: Evangraf, 2001. 152p. 